\title{
Transcriptional activity of telomerase complex in CD34- stem cells of cord blood in dependence of preparation time
}

\author{
R. Stojko1, A. Witek¹, J. Głogowska-Lingus², U. Mazurek², G. Chromy¹, \\ T. Dworzecki', M. Bojdys-Szyndlar ${ }^{1}$, K. Machaj ${ }^{3}$, Z. Pojda 3 \\ ${ }^{1}$ Gynaecology and Obstetrics Department, Medical University of Silesia, Katowice, Poland \\ ${ }^{2}$ Department of Molecular Biology, Medical University of Silesia, Sosnowiec, Poland \\ ${ }^{3}$ Department of Experimental Haematology, M. Skłodowska-Curie Memorial Cancer Center, \\ Warsaw, Poland
}

\begin{abstract}
The aim of the study was to determine whether the expression of telomerase subunits encoding genes changes during the process of cord blood preparation. It should establish if the commonly accepted 24 hours time interval in stem cells kriopreservation procedure significantly influences their immortalization and so decreases the "quality" of cord blood stem cells. Investigation includes 69 women. Spontaneous labour was the inclusion condition. The material was collected at birth after clamping of umbilical cord by direct vasopuncture. CD34- cells were extracted from cord blood (MACS, Miltenyi Biotec; Bisley, Surrey, UK). The expression profile of telomerase activators and inhibitors encoding genes was determined using HG_U133A oligonucleotide microarray (Affymetrix). We used a real-time quantitative RT-PCR assay to quantify the telomerase TERT, hTR and TP1 subunits mRNA copy numbers in CD34- cells in 0, 6, 12 and 24 hours after cord blood collection. We observed significant decrease of numbers of copies of TERTA+B mRNA within the successive hours of observation. Significant decrease of numbers of TERTA mRNA copies was confirmed after 24 hours. However, we observed significant increase of numbers of copies of TERTB mRNA after 6 hours of observation. Similar level was maintained during another $6 \mathrm{~h}$. The significantly lower number of copies of TERTB mRNA was observed after $24 \mathrm{~h}$. We also observed significant increase of number of copies of TERT mRNA after 6 hours. Number of copies of TERT mRNA significantly decreased after another 6h, remaining, however, on a higher then initial one. The significant lower number of copies of TERT mRNA was observed $24 \mathrm{~h}$ after delivery. The possible explanation of those results is discussed in the paper.
\end{abstract}

Key words: cord blood, stem cells, microarrays, telomerase subunits encoding genes, transcriptional activity.

\section{Introduction}

The fast developing life science and genetics in the last century brought to appearance of new therapeutic methods leaning towards the use of cord stem cells. Research over improvement of cell cultures methods, composition of mediums, and use of various factors stimulating cell proliferation (growth factors, cytokines, chemokines and hormones) are bringing

Correspondence: R. Stojko, Gynaecology and Obstetrics Department, Medical University of Silesia, Katowice, Poland; tel.: (+4832) 7894731, fax.: (+4832) 7894732,

e-mail: rstojko@slam.katowice.pl medicine closer to the wide clinical use of stem cells. Immortalization, which means preservation of telomers after each and every stem cell's division, is one of characteristic features of stem cells determining their potential use in medicine. The factor that prevents telomers shortening after division of a stem cell is telomerase. Also normal somatic cells such as hemotopoietic cells, cervical epithelial cell and endometrial cell, all of which have high regenerative potential, are also known to express telomerase activity.

Telomerase is a reverse transcriptase which adds repetitive telomere sequences to the end of chromosomes which is thought to be essential for cellular immortality. The enzyme consists of three subunits: 
hTERT (human telomerase reverse transcriptase) (synonim TCS1, EST2) - a subunit of an activity of reverse transcriptase; hTR (human telomerase RNA) (synonim TERC, TRC3, TR) of the matrix section of RNA; and TP1 - an accompanying protein of an unknown function. The hTERT subunit determines the activity of telomerase as an enzyme. Many studies have revealed that hTR and TP1 is expressed constitutively. The presence of TERT and hTR subunits makes possible the activity of telomerase in vitro. This second subunit is the matrix for the hTERT polimerase. hTR is an RNA fragment complementary to telomer sequence. In the cell is postulated the presence of whole complex which controls telomerase activity. Among the proteins binding with hTERT and hTR highlited the TP1 protein (telomerase protein 1). TP1 has ability to bind to hTERT and hTR.

Telomerase activity is connected with cells proliferation and differentiation. The majority of regular human cells do not show an expression of a gene of hTERT subunit or the enzymatic activity of the complex, despite the presence of the other components. Only the expression of a gene for the catalytic subunit hTERT enables cells to demonstrate the telomerase activity. This observation proves that the hTERT subunit is a determining factor of the in vivo activity of the entire complex. The control of hTERT expression is crucial to extension of proliferation and immortalization potential. Therefore, it is accepted that one of the markers of immortalization activity of cord blood stem cells is the presence of the telomerase complex, especially its hTERT subunit together with its functionally vital isoforms A and B.

In this study we presented the transcriptive activity of telomerase complex of cord blond CD34- stem cells with respect to the duration time of preparation process in healthy pregnant women. The important problem concerning stem cells is the preparation process which takes place between their collection and freezing. Within the over a dozen years of existence of cord blood banks all over the world, it was agreed that the entire preparation process should be finished within $24 \mathrm{~h}$ from collection. This is due to the hypothetic decrease of stem cells vitality with time after the collection. Duration of that procedure and its influence on the "quality" of frozen material is the subject of this study.

The aim of the study was to estimate the dynamics of change in stem cells immortalization potential during preparation of cord blood by measuring the expression of telomerase subunit encoding genes in cord blood stem cells directly after collection as well as 6 , 12 and 24 hours after collection. It should allow establishing if commonly accepted 24 time interval in procedure of stem cells kriopreservation is suitable for their "quality".

\section{Materials and methods}

Patients. Research group included 69 healthy patients between 18 and 35 years old, hospitalized in the Department of Obstetrics and Gynecology, Medical University of Silesia, Katowice, Poland. The inclusion criteria were spontaneous physiological labor and no health problems before or during pregnancy. Among that group, 35 women agree to participate in the research. Out of those 35 patients, 22 women were primiparas, 12 patients labored for the second time and 1 woman for the third time.

Cord blood preparation. The studied material was taken at birth and after clamping of umbilical cord by direct vasopuncture of umbilical vessels after previous sterilization of a place of puncture. The entire procedure was held before the end of third stage of labour. Human umbilical cord blood samples were collected directly into sterile tubes with reduced content of anticoagulant. The blood was transported to The Department of Molecular Biology in accordance with standard procedure executed through the cryopreserve centres.

Studied material was quartered. First part was frozen in $-20^{\circ} \mathrm{C}$ just after collection, second six hours after, third twelf hours and fourth twenty four hours after collection.

CD34- cells extraction from cord blood. The cord blood was diluted with PBS (Gibco) and in proportion 2:1 with Ficoll (Sigma). Diluted cord blood was centrifuged at $400 \mathrm{xg}$ for $40 \mathrm{~min}-$ utes in $20^{\circ} \mathrm{C}$. A Peripheral Blood Mononuclear Cells were then transferred to a medium with addition of serum and centrifuged at $200 \mathrm{xg}$ for 10 minutes in $20^{\circ} \mathrm{C}$.

The cell suspension was incubated with blocking reagent and a CD34 antibody from the CD34 Isolation Kit (MACS, Miltenyi Biotec; Bisley, Surrey, UK) for $15 \mathrm{~min}$ at $4-8^{\circ} \mathrm{C}$. After incubation, the cells were washed in PBS and resuspended in $400 \mu 1$ of the same buffer. $100 \mu \mathrm{l}$ of immunomagnetic bead suspension conjugated to an antimouse antibody were then added to the cells, and incubation continued for a further $15 \mathrm{~min}$ in the cold. After washing, the $\mathrm{CD} 34^{+}$cells were isolated by passing the cells suspension through a column placed in a magnetic field which allowed retention of the target cells. The magnetic field was then removed, and the $\mathrm{CD} 34^{+}$cells were flushed from the column with PBE buffer. The number of cells was then determined by fluorescence measurement after incubation of CD34+ cells with anty-CD34 (BD) monoclonal antibodies conjugated with IgG1 antibodies (Becton Dickinson). Amount of leukocytes, mononuclear cells, erytrocytes and trombocytes was determined by haematologic analyser Sysmex (Toa Medical Electronic). Cells vitality was marked in fluorescent microscope after labelling by ethidium bromide and acridine orange. Number of CD34+ cells was analysed by flow cytometry using monoclonal antibody anti-CD 34 coupled to phycoerythrin or IgG1 antibody (Becton Dickinson). Fluorescence was then analyzed by FACSCalibur ${ }^{\mathrm{TM}}$ flow cytometer (Becton Dickinson) and CELLQuest ${ }^{\mathrm{TM}}$ software (Becton Dickinson). The analysis was carried out with the use of FACSCalibur (BD) device and CELLQuest (BD) program. CD34- cells were isolated in Departament of Experimental Hematology of Oncology Insitute, Warsaw.

CD34- cells culture. The CD34- cell line was maintained in Iscove's Modified Dulbecco's Medium (IMDM) (Gibco Invitrogen) with penicillin/streptomycin and $5 \%$ bovine serum albumin.

RNA extraction. Total cellular RNA was extracted from CD34cells using TRIzol (GibcoBRL). All extracts were treated with DNA-se I to avoid contamination of genomic DNA. RNA was purified on RNeasy Mini Kit columns (Qiagen). RNA extracts were qualitatively evaluated by electrophoresis in 1,5\% agarose gel and quantitatively by spectrophotometry (Gene Quant II by LKB Pharmacia Biotech). 
Microarray Assay. The oligonucleotide microarray method is the semi-quantitative analysis. The oligonucleotide microarray technology platform simultaneously analyzes the relative expression levels of genes. The expression profile of telomerase activators and inhibitors encoding genes was determined using HG U133A oligonucleotide microarray (Affymetrix). In order to obtain the first thread of cDNA, to $8 \mu \mathrm{g}$ of RNA $1 \mu \mathrm{l} 100 \mathrm{pM}$ of starter T7-oligo (dT) ${ }_{24}$ (5'GCCAGTGAATTGTAATACGACTCACTATAGGGAGGCGG-3') was added, the mixture was incubated at $70^{\circ} \mathrm{C}$ for 10 minutes and placed in ice. Starter included promoter sequence for RNA - phageT7-polymerase (Invitrogen). Then the following was added to the reaction, in this order: $4 \mu$ of $5 \times$ First Strand Buffer, $2 \mu \mathrm{l}$ of $0,1 \mathrm{M} \mathrm{DTT}$, and $1 \mu \mathrm{l}$ of $10 \mathrm{mM}$ dNTPs. After 2 minutes of pre-incubation at $42^{\circ} \mathrm{C}, 2 \mu \mathrm{l}(200 \mathrm{U})$ of reverse transcriptase Superscript II (Life Technologies) was added to the reactive mixture and incubation was continued for another hour. In order to obtain the second thread of cDNA, the following was added to the reaction: $30 \mu 1$ of $5 \times$ Second Strand Buffer, $91 \mu 1$ of RNase-free water, $3 \mu \mathrm{l}$ of $10 \mathrm{mM}$ dNTPs, $4 \mu \mathrm{l}$ (40 U) of E. coli DNA Polymerase I (Life Technologies), $1 \mu \mathrm{l}$ (10 U) of E. coli DNA Ligase (TaKaRa), $1 \mu$ of ( $2 \mathrm{U})$ Rnase $\mathrm{H}$ (TaKaRa). The mixture underwent 2 -hour incubation at $16^{\circ} \mathrm{C}$. After that time, $2.5 \mu \mathrm{l}(10 \mathrm{U})$ of T4 DNA Polymerase I (TaKaRa) was added to the mixture, and the entire mass underwent incubation at $16^{\circ} \mathrm{C}$ for another 5 minutes. The reaction was blocked by adding $10 \mu \mathrm{l}$ of 0,5 M EDTA whereas the double-thread cDNA (ds cDNA) was extracted by using the phenol/chloroform method. The aqueous phase was separated using Phase Lock Gel (Eppendorf). After precipitation, cDNA was dissolved in $12 \mu \mathrm{l}$ of water free from RNases. $10 \mu \mathrm{l}$ of ds cDNA constituted the matrix for synthesis of biotinilised cRNA (BioArray High Yield RNA Transcript Labeling Kit, Enzo Diagnostic). The marked cRNA was purified in columns of RNeasy Mini Kit (Qiagen), fragmented and hybridized, first with test micromatrix (Test3), and then with the micromatrix of Human Genome Arrays U133A (Affymetrix). Washing, staining with streptavidyne-phycoerythrine complex and scanning of micromatrix in GeneArray (Agilent) scanner was carried out in line with the instructions of Affymetrix Gene Expression Analysis Technical Manual. The absolute and comparative analyses were carried out by means of the software Affymetrix GeneChip Analysis Suite 5.0. The results obtained after comparative analysis were then sorted to single out genes with changed expression, using the software Affymetrix Data Mining Tool.

The results were normalized using RMAExpress. Next the hierarchical clustering analysis was used for each tested group, based on Cluster v.3.0. It is an agglomerative approach in which single expression profiles are joined to form groups, which are further joined until the process has been carried to completion, forming a single hierarchical tree. There are several variations on hierarchical clustering. We used single-linkage hierarchical clustering using an Euclidean distance metric showing the differences in expression levels among analyzed measurements.

The aim of this analysis was comparison of transcriptional activity of telomerase activators and inhibitors encoding genes in CD34- cell cultures obtained from cord blood directly after collection and 24 hour after collection. Data included three CD 34- cell cultures. Cultures 1 and 2 were made of cells obtained from cord blood directly after collection and cell culture $3-24$ hour after. CD34- cell cultures was divided additionally into two fractions: cells CD 34- adjacent (A) and not adjacent (NA) to plastic.

Real Time PCR assay (QRT-PCR). We performed a real-time quantitative RT-PCR assay to quantify the numbers of copies of mRNA of telomerase subunits (TERT, hTR and TP1) in CD34cells obtained directly after childbirth and 6,12 and 24 hours after cord blood collection. Transcriptional activity of telomerase sub- units encoding genes is expressed as numbers of copies of a given mRNA (TERT, hTR and TP1) per $1 \mu \mathrm{g}$ of total RNA appointed on the basis of kinetics of real-time PCR.

Analysis of the expression of hTERT, hTR and TP1 telomerase subunits was performed by quantitative polymerase chain reaction method based on fluorescent TaqMan methodology (ABI Prism 7000 Sequence Detection System) capable of measuring fluorescence in real-time.

Primers for amplification of telomerase subunits (TERT, hTR and TP1) were determined using the computer program Primer Express ${ }^{\mathrm{TM}}$ Version 1.0 (Perkin-Elmer Applied Biosystems, Foster City, CA) and checked by BLAST. Primers sequence was: TERT-2161 5'-CGCCGCCTGAGCTGTACTTTGTC-3' (sense), TERT-2611 5'-TTGTTCTCCATGTCGCCGTAG CA-3' (antisense) for hTERT subunit; TERT-2191A 5'-ATGTGACGGGCGCGTACGAC-3' (sense), TERT-2611 5'-TTGTTCTCCATGTCGCCGTAGCA-3' (antisense), for hTERTA subunit; hTR-24 5'-AGGCGCCGTGCTTTTGCTCC-3' (sense), hTR-146 5'-GGCCAGCAGCTGACATTTTTTGTT T-3' (antisense) for hTR and TP1-2769 5'-GCAGCATCCGGCTTTTCATTTCA-3' (sense), TP1-3138 5'- TGCAGACGTTGGTTCCGGTTCAG -3' (antisense) for TP1. We performed BLASTN to confirm the total gene specificity of the nucleotide sequences chosen as primers and probes. Total RNA was reverse-transcribed for single strand cDNA using Tth polymerase. QRT-PCR was performed using the ABI PRISM7000 Sequence Detection System (RT: $50^{\circ} \mathrm{C}-30$ min.; polymerase activation $95^{\circ} \mathrm{C} 15$ min.; PCR: 45 cycles: $94^{\circ} \mathrm{C}$ - $15 \mathrm{~s}, 60^{\circ} \mathrm{C}-30 \mathrm{~s}$, and elongation $72^{\circ} \mathrm{C}-10 \mathrm{~min}$.). Quantified transcripts of the gene GAPDH encoding human glyceraldehyde-3-phosphate dehydrogenase (using oligonucleotide 5'-GAAGGTGAAGGTCGGAGTC-3' as forward primer and 5'-GAAGATGGTGATGGGATTC-3' as reverse primer) and $\beta$-actin (using oligonucleotide 5'-TCACCCACACTGTGCCCATCTACGA-3' as forward primer; 5'-CAGCGGAACCGCTCATTGCCAATGG-3' as reverse primer and 5'-ATGCCCTCCCCCATGCCATCCTGCGT-3' as probe) gene as an endogenous RNA control were carried out. The copy number of each sample is inferred from the $\mathrm{C}_{\mathrm{T}}$ and by using the standard curve performed during the same experiment. The number of ERalpha mRNA copies was calculated based on the calibration curve for $\beta$-actin standards performed during the same experiment. The obtained results were recalculated for $1 \mu \mathrm{g}$ of total RNA. Primers and probe specifics were confirmed by sequence analysis using ABI PRISM 377 DNA Sequencer (PE Applied Biosystems).

Ethical issues. Consent for the experiment was obtained from The Research Committee for Human Subjects of The Medical University of Silesia.

Statistical analysis. Statistical analysis was performed with the use of STATISTICA data analysis software system (StatSoft, Inc. 2001, version 6. www.statsoft.com). Thus, the normal distribution was calculated using Shapiro-Wilk test and showed lack of such distribution, therefore, to assess differences between particular groups nonparametric test (Wilcoxon-Cox test) and parametric t Student and Welch's tests (t-test corrected for unequal variances) were employed, at the $p=0.05$ significance level. The dynamics of changes of analyzed parameters levels was presented graphically in figure of temporary courses. The Lilliefors and Bera-Jarque normality tests were used for nonparametric residuals. We used Grubbs' algorithm. This algorithm assumes that the finite observations of a study are taken from a Gaussian population.

Comparisons between time-intervals were made independently in subgroups, using $t$ test or Wilcoxon-Cox test. Calculations were done with use R language (http://www.bioconductor.org/) as well as Matlab system (http://www.mathworks.com/). 


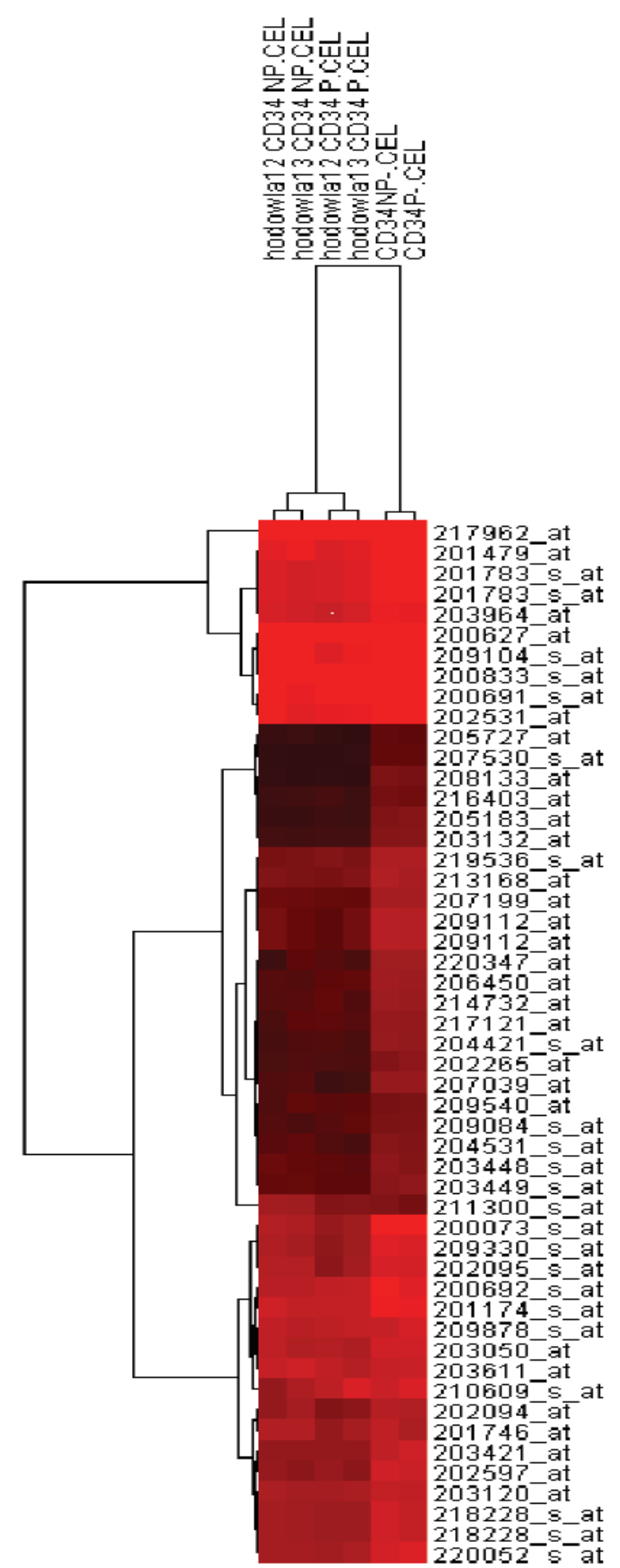

Fig. 1. Dendrogram for all transcripts of telomerase activators and inhibitors based on normalized fluorescence value. Genes in the demonstration data set were subjected to single-linkage hierarchical clustering using a Euclidean distance metric and gene-expression families.

\section{Results}

\section{Microarray Assay}

Transcriptional activity of telomerase activators and inhibitors encoding genes. Fig. 1 presents the obtained results of clustering. Clusterization was car-

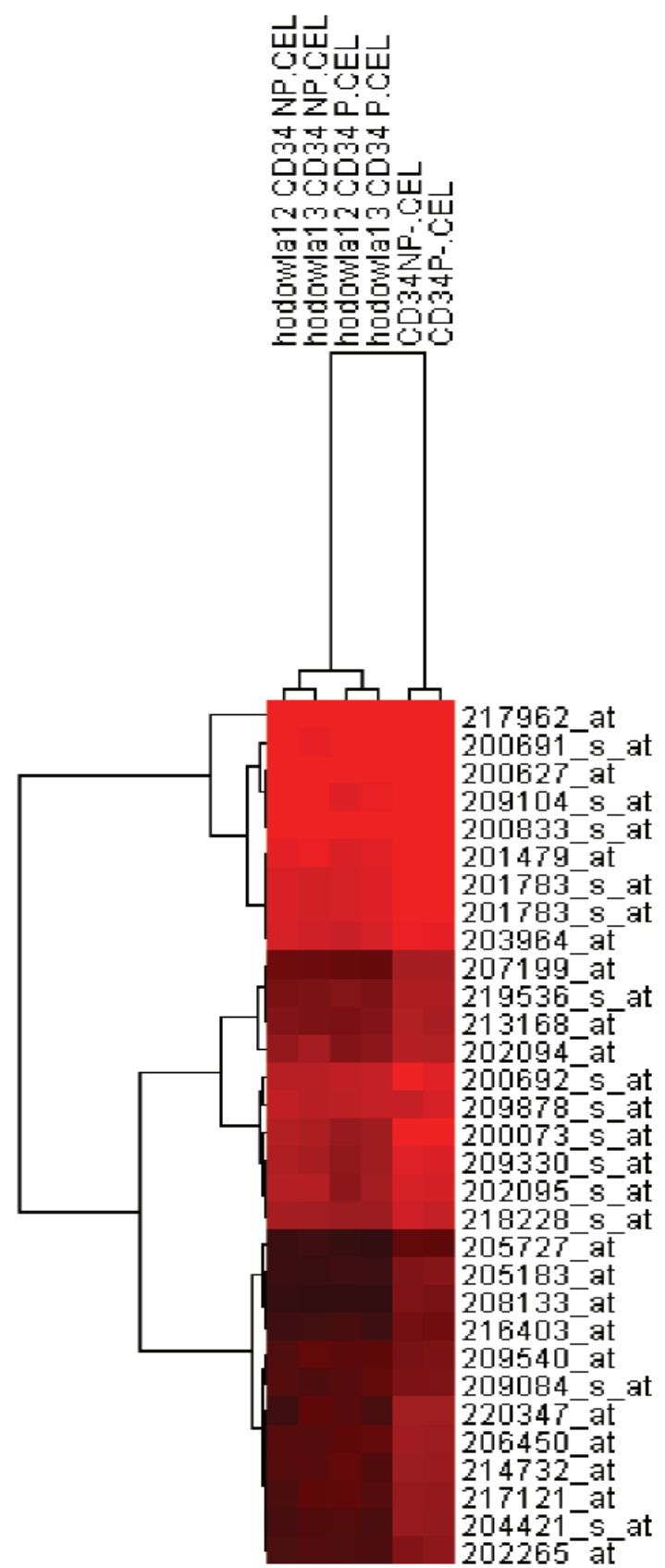

Fig. 2. Dendrogram for all transcripts of telomerase activators based on normalized fluorescence value. Genes in the demonstration data set were subjected to single-linkage hierarchical clustering using a Euclidean distance metric and gene-expression families.

ried out for all transcripts of telomerase activators and inhibitors. The dendrogram shows the correlation between expression profiles of transcripts of telomerase activity regulators encoding genes.

Hierarchical clustering yielded three groups of separate clusters. The first group includes CD 34- cells adjacent to plastic. The second group consists of CD 34cells not adjacent to plastic. And the last group includes CD 34- cells adjacent and not adjacent to plastic. 


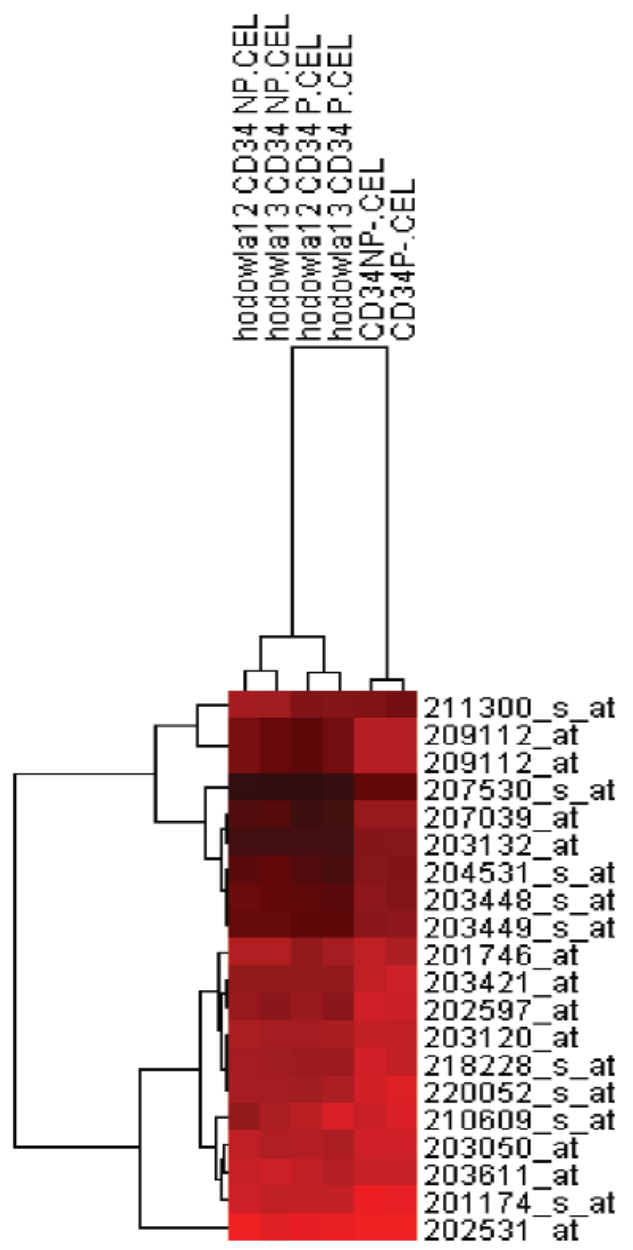

Fig. 3. Dendrogram for all transcripts of telomerase inhibitors based on normalized fluorescence value. Genes in the demonstration data set were subjected to single-linkage hierarchical clustering using a Euclidean distance metric and gene-expression families.
Hierarchical clustering yielded three groups of separate clusters. The first group includes CD 34- cells adjacent to plastic. The second group consists of CD 34cells not adjacent to plastic. And the last group includes CD 34- cells adjacent and not adjacent to plastic.

Hierarchical clustering yielded three groups of separate clusters. The first group includes CD 34- cells adjacent to plastic. The second group consists of CD 34cells not adjacent to plastic. And the last group includes CD 34- cells adjacent and not adjacent to plastic.

Differentiating genes of CD34- cell cultures obtained directly after childbirth and 24 hours after cord blood colection. To identify differentiating genes from groups of telomerase activators and inhibitors, linear regression was performed. The regression model is indexed with biologically meaningful gene-specific parameters.

In regression analysis apart from the statistical criterion, realizing the possible delimitation round line of regression the area of prognosis is regarded as the biological criterion. The biological criterion is defined as twofold increase or decrease in value of gene expression.

The statistical criterion (the prognosis area) implicates the biological criterion: differentiating gene: (TERT - telomerase reverse transcriptase; ID:207199_at) (Fig.4) are located above the statistical criterion.

The statistical criterion (the prognosis area) implicates the biological criterion: differentiating gene: (RELA - reticuloendotheliosis viral oncogene homolog A; ID: 209878_s_at) (Fig.5) are located on border of statistical criterion.

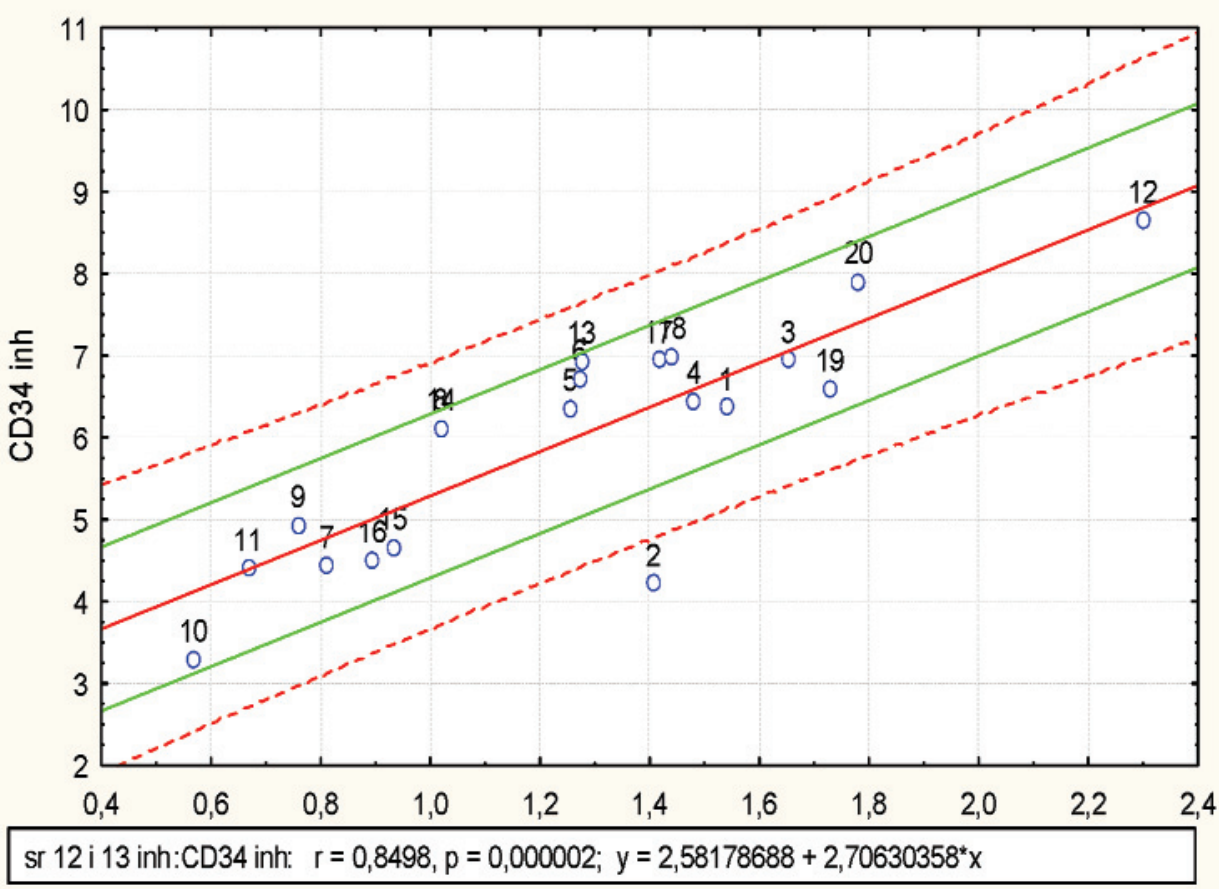

Fig. 4. Regression analysis for normalized fluorescence value of telomerase inhibitors transcripts in CD34- cell cultures obtained directly after childbirth and 24 hour after cord blood collection. 


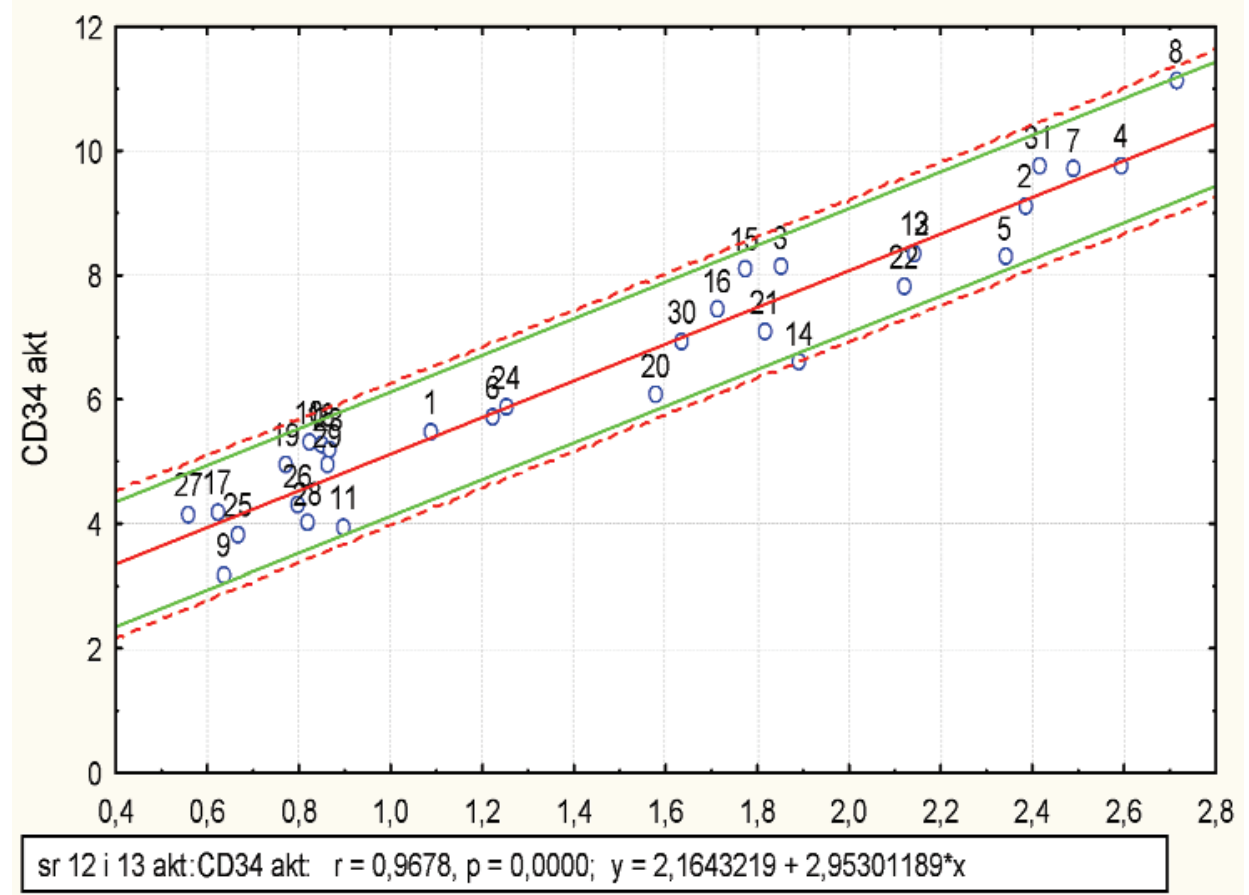

Fig. 5. Regression analysis for normalized fluorescence value of telomerase activators transcripts in CD34cell cultures obtained directly after childbirth and 24 hour after cord blood collection.

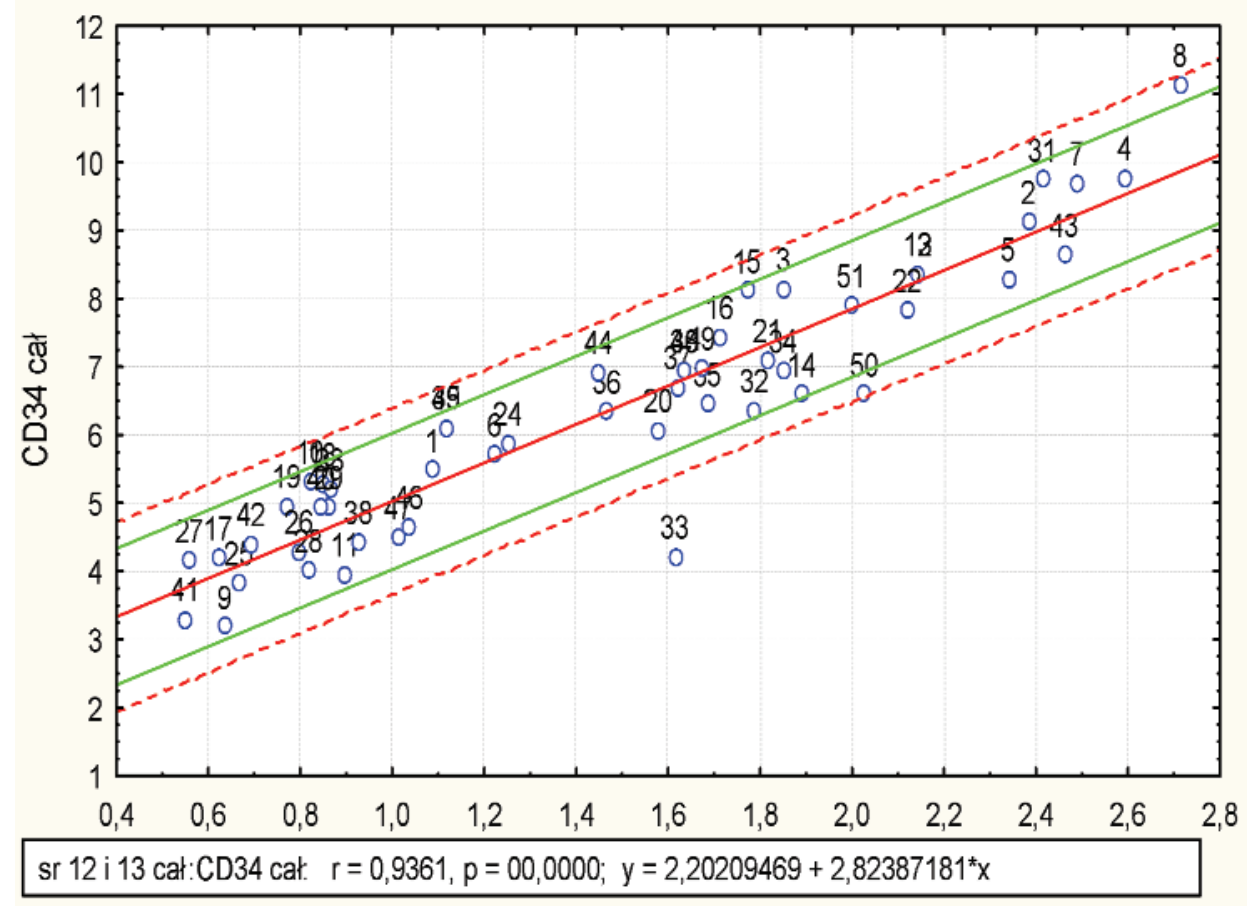

Fig. 6. Regression analysis for normalized fluorescence value of telomerase regulators transcripts in CD34cell cultures obtained directly after childbirth and 24 hour after cord blood collection.
The statistical criterion (the prognosis area) implicates the biological criterion: differentiating gene: (P53 - tumor protein P53; ID: 211300_s_at) (Fig.6) are located above statistical criterion.

\section{Real Time PCR assay (QRT-PCR)}

Transcriptional activity of hTR telomerase subunits encoding gene in CD34- cells. Transcriptional activity of hTR encoding gene was analysed in CD34cells obtained in different time-intervals $(0 \mathrm{~h}, 6 \mathrm{~h}, 12 \mathrm{~h}$ and $24 \mathrm{~h}$ from collection) from women after spontaneous labour. The average of transcriptional activity of hTR encoding gene equaled 24567 mRNA copies in $0 \mathrm{~h} ; 21456$ copies of mRNA in $6 \mathrm{~h} ; 22456$ in $12 \mathrm{~h}$ and 25467 mRNA copies in $24 \mathrm{~h}$.

The Levene's test for equality of variances and Wilcoxon test were used to evaluate the variation of 


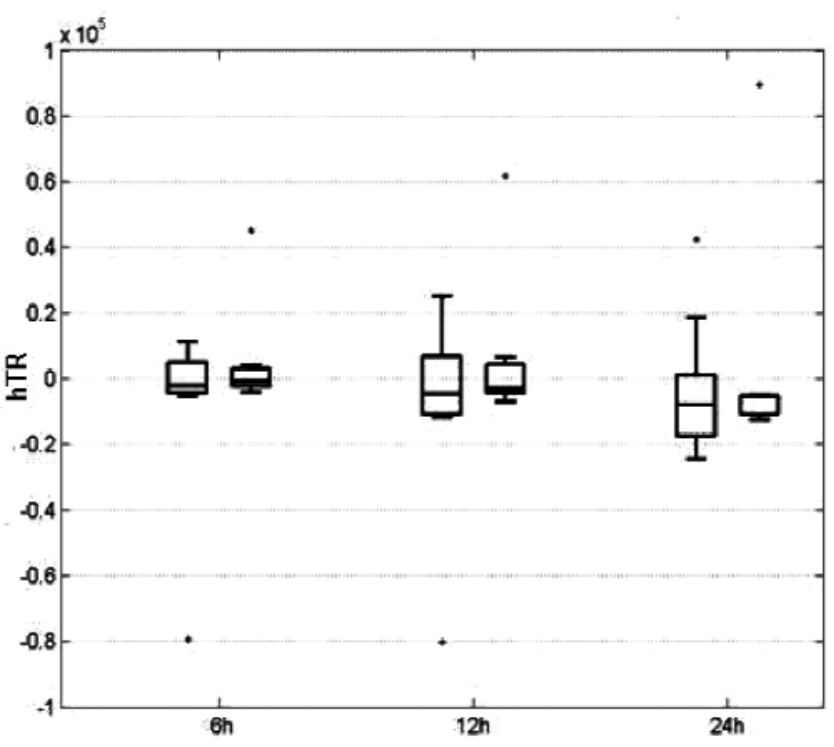

Fig. 7. Comparison of hTR mRNA copies per $\mu \mathrm{g}$ of total RNA between $0 \mathrm{~h}, 6 \mathrm{~h}, 12 \mathrm{~h}$ and $24 \mathrm{~h}$ after cord blood collection.

numbers of copies of hTR mRNA in successive timeintervals. Numbers of copies of hTR mRNA were not significantly different between all time-intervals $(0 \mathrm{~h}$, $6 \mathrm{~h}, 12 \mathrm{~h}$ and $24 \mathrm{~h}$ from collection) in CD34- cord blood cells obtained from women with spontaneous labour (Levene's test; $\mathrm{p}=0.18$; Wilcoxon test; $\mathrm{p}>0.05$ ).

Transcriptional activity of TERT telomerase subunits encoding gene in CD34- cells. Transcriptional activity of TERT encoding gene was analysed in CD34- cells obtained in different time-intervals $(0 \mathrm{~h}$, $6 \mathrm{~h}, 12 \mathrm{~h}$ and $24 \mathrm{~h}$ from collection) from women after spontaneous labour.

Telomerase TERT A+B isoform of TERT subunits. The TERTA+B isoform mRNA copy numbers was compared in different time-intervals. The Levene's test for equality of variances and Wilcoxon test were used to evaluate the variation of numbers of copies of TERTA+B isoform mRNA in successive time-intervals (Fig. 8). Our results revealed a significant decrease of TERTA $+\mathrm{B}$ mRNA copy numbers in the following time interval: $0 \mathrm{~h} v s .24 \mathrm{~h}(\mathrm{p}=0,008250$; $\mathrm{t}$ Student test).

TERTA isoform of TERT telomerase subunits. The Levene's test for equality of variances and Wilcoxon test were used to evaluate the variation of TERTA isoform mRNA copy numbers in consecutive time-intervals (Fig. 9).

There was a significant decrease of TERTA mRNA copy numbers after 24 hours of observation

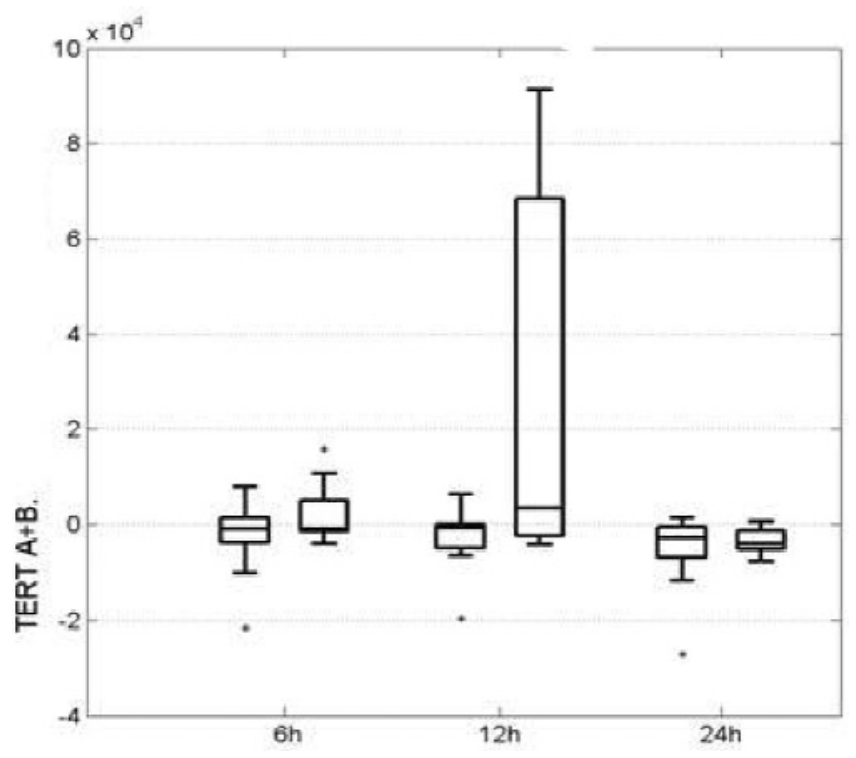

Fig. 8. Comparison of TERTA+B mRNA copies per $\mu \mathrm{g}$ of total RNA between $0 \mathrm{~h}, 6 \mathrm{~h}, 12 \mathrm{~h}$ and $24 \mathrm{~h}$ after cord blood collection.

$(\mathrm{p}=0.002291 ; \mathrm{t}$ Student test). Changes were not observed in the first $12 \mathrm{~h}$.

TERTB isoform of TERT telomerase subunits. The Levene's test for equality of variances and Wilcoxon test were used to evaluate the variation of TERTB isoform mRNA copy numbers in consecutive time-intervals (Fig.10).

We observed significant increase of TERTB mRNA copy numbers after 6 hours of observation ( $\mathrm{p}=0.005788 ; \mathrm{t}$ Student test; 0h vs. 6h). This level was similar after next $6 \mathrm{~h}$. The decrease of TERTB mRNA copy numbers occured after 12 hours from blood collection ( $p=0.000021$; $t$ Student test). The significant lower TERTB mRNA copy numbers was observed after $24 \mathrm{~h}$ from childbirth $(\mathrm{p}=0.000082 ; \mathrm{t}$ Student test).

Telomerase TERT subunits. The Levene's test for equality of variances and Wilcoxon test were used to evaluate the variation of TERT mRNA copy numbers in next time-intervals (Fig.11).

We observed significant increase of TERT mRNA copy numbers after 6 hours of observation $(\mathrm{p}=0.000439$; $\mathrm{t}$ Student test). Numbers of copies of TERT mRNA was reduced after next $6 \mathrm{~h}(\mathrm{p}=0.029697$; t test). However, it remained on a higher level than at initial moment $(\mathrm{p}=$ 0.036305; t Student test). The significantly lower TERT mRNA copy numbers was observed after $24 \mathrm{~h}$ from childbirth ( $\mathrm{p}=0.008115$; $\mathrm{t}$ Student test).

Telomerase TP1 subunits. Transcriptional activity of TP1 encoding gene was analysed in CD34- cells 


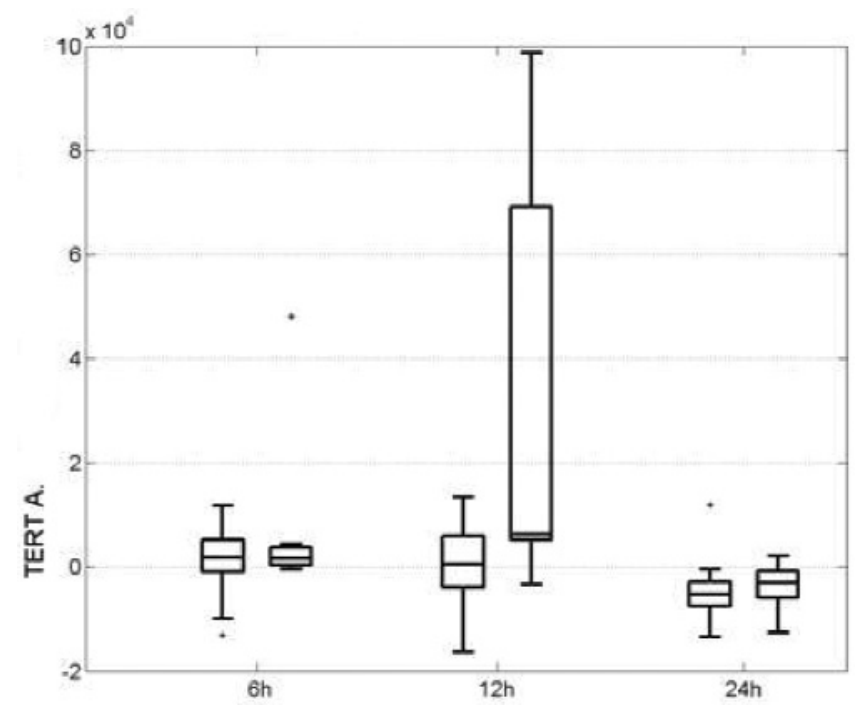

Fig. 9. Comparison of TERTA mRNA copies per $\mu \mathrm{g}$ of total RNA between $0 \mathrm{~h}, 6 \mathrm{~h}, 12 \mathrm{~h}$ and $24 \mathrm{~h}$ after cord blood collection.

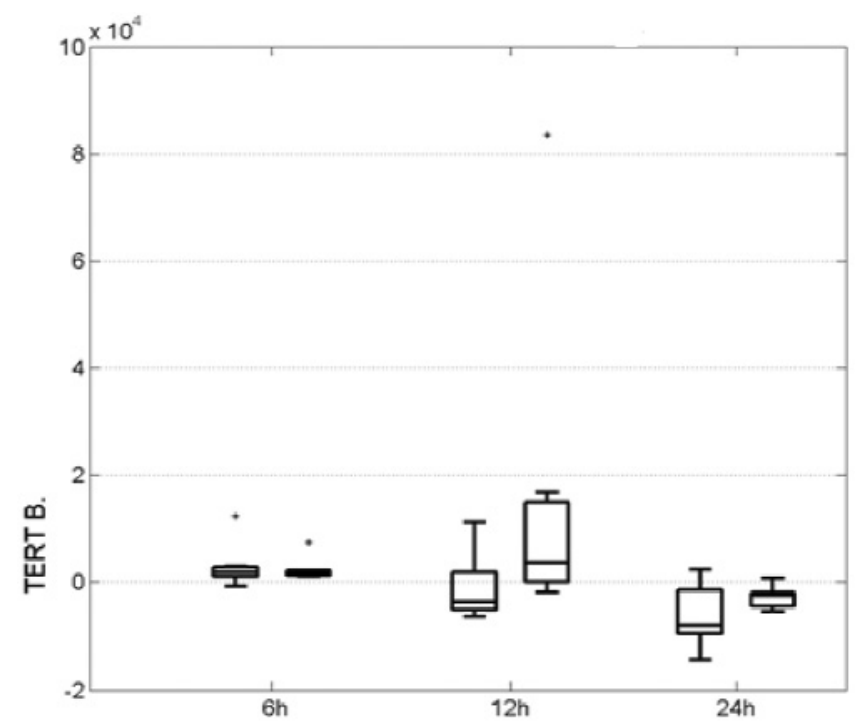

Fig. 10. Comparison of TERTB mRNA copies per $\mu \mathrm{g}$ of total RNA between $0 \mathrm{~h}, 6 \mathrm{~h}, 12 \mathrm{~h}$ and $24 \mathrm{~h}$ after cord blood collection.

obtained in different time-intervals $(0 \mathrm{~h}, 6 \mathrm{~h}, 12 \mathrm{~h}$ and 24h) from women after spontaneous labour.

The Levene's test for equality of variances and Wilcoxon test were used to evaluate the variation of TP1 isoform mRNA copy numbers in next time-intervals (Fig.12).

Significant increase of number of copies of TP1 mRNA was observed between $0 \mathrm{~h}$ and $12 \mathrm{~h}$ after cord blood collection ( $\mathrm{p}=0.038607$; Wilcoxon test). After 24h TP1 mRNA copy number did not differ significantly from initial value. The biggest change in TP1 mRNA copy number was observed between $6 \mathrm{~h}$ and 12 h (p 0.013064; Wilcoxon test).

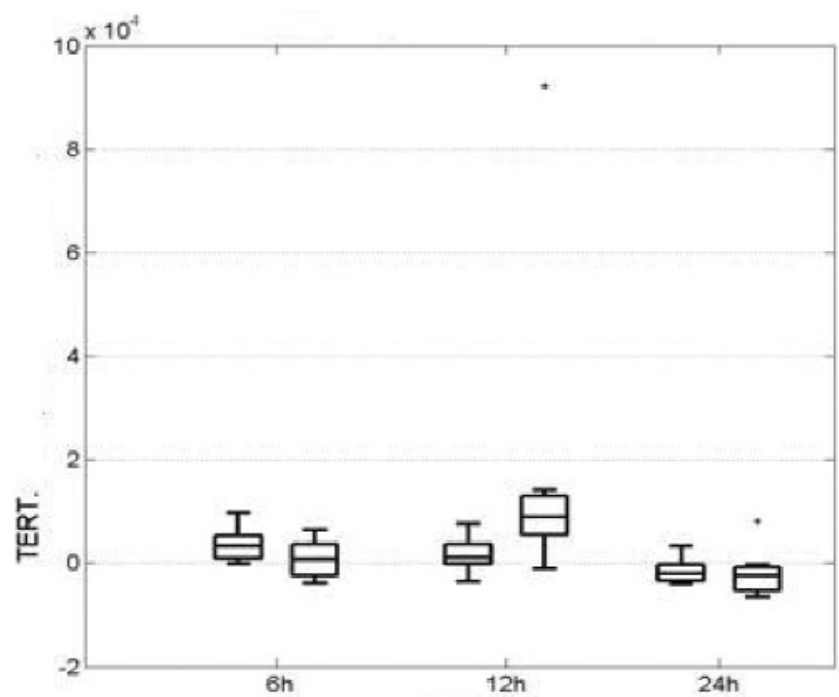

Fig. 11. Comparison of TERT mRNA copies per $\mu \mathrm{g}$ of total RNA between $0 \mathrm{~h}, 6 \mathrm{~h}, 12 \mathrm{~h}$ and $24 \mathrm{~h}$ after cord blood collection.

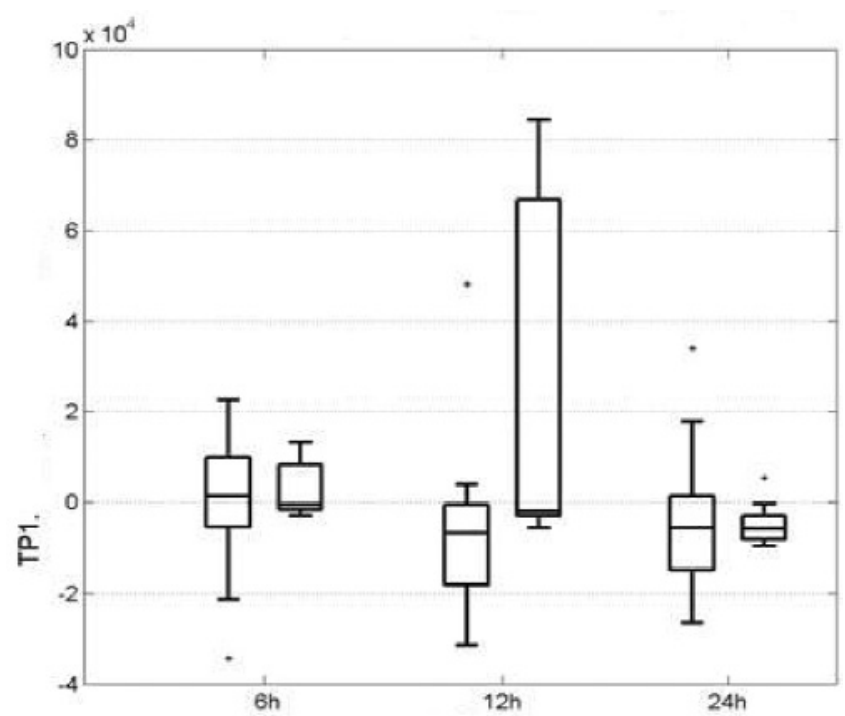

Fig. 12. Comparison of TP1 mRNA copies per $g$ of total RNA between $0 \mathrm{~h}, 6 \mathrm{~h}, 12 \mathrm{~h}$ and $24 \mathrm{~h}$ after cord blood collection.

\section{Discussion}

Latest research give evidence that telomerase can be regarded as an enzyme of immortality not only because it counteracts the natural process of aging (by inhibiting the telomeres shortening) but also because expression of that enzyme prevents apoptosis, normally caused by factors damaging cells. Although the mechanism of that action has not been fully revealed yet, there are many reports showing that induced overexpression of telomerase in various types of cells (including ESC) enables them to survive the genotoxic stress and facilitates cell culturing [1-9]. Other papers show that expression of telomerase increases when stress in 
inflicted upon some types of cells [10-12]. Hence, there are reasons to believe that the increase of expression of telomerase is a natural response of certain types of cells to unfavorable environment which otherwise could lead to apoptosis. Such response can be treated as cells defense against apoptosis.

Certainly, one of such harmful factors, to which stem cells may be subjected and which can decrease the number of stem cells obtained from cord blood is hypoxia. Though some research report that hypoxia (3\% or even $1 \%$ concentration of oxygen; in comparison to $14 \%$ in arterial blood and $5-7 \%$ in bone morrow) has a positive influence on stem cell culturing and expression of telomerase [13,14], we cannot assume that in the course of preparation of cord blood the concentration of oxygen does not fall below the critical values, harmful to stem cells.

However, the rise of telomerase expression might have been also induced by response of the whole newborns body to perinatal stress. Vaginal delivery is certainly a stress situation for the newborn and it is confirmed by works comparing physiological delivery and delivery by cesarean section. Such papers show higher level of cortisol in cord blood after vaginal delivery than after cesarean section [15-17]. Vogl et al. showed that levels of adrenalin, noradrenalin and ACTH are also elevated in vaginal deliveries in comparison to cesarean sections. Additionally, Malamitsi-Puchner et al. [18] found out that concentrations of some cytokines (IL-1beta, IL-6, TNF-alpha, IFN-gamma) are higher in cord blood and peripheral blood of the newborns delivered vaginally then by cesarean section. Interestingly, other authors $[19,20]$ correlated one of those cytokines (IL-6) with markers of perinatal stress such as cord blood $\mathrm{pH}$, higher number of NRBC or elevated concentration of cortisol. IL- 6 is in turn a factor which is thought to induce the expression of telomerase [21-26]. Basing on that information, it is probable that the increase of telomerase expression could be also caused be the perinatal stress mediated by cytokines.

Taking the above mentioned into consideration, the rise in telomerase expression after 6 hours from collection observed in our work does not seem to be a desirable event. Being cells protection against apoptosis such rise proves that stem cells environment after cord blood collection is unfavorable. Similar conclusion can be drown from papers reporting decreasing number of CD34 + stem cells (Nakagawa) [27] as well as CD34- stem cells (Bieback) [28] with time from cord blood collection.

However, our results may give evidence that immortalization potential of MSC is present and is not impaired until the sixth hour from collection. Moreover, our results show that telomerase activity changes comparably fast, accurately reflecting cells actual con- dition. Hence, it suggests that telomerase could be a good marker of stem cells "quality" expressed as an ability to inhibit apoptosis and so as an ability to sustain stress inflicted on a cell.

Regardless to causes of the rise of telomerase expression, its fall undoubtedly marks the critical moment when cells ability to sustain stress comes to an end. It also proves that 24 hours preparation time is long enough to significantly impair stem cells metabolism. The decrease in stem cells count with longer time of preparation described by Nakagawa and Bieback suggest that the process of preparation is unfavorable for the cord blood stem cells. Such decrease may be explained by the above mentioned depletion of stem cells compensation mechanisms one of which could be the ability to express telomerase. Bieback reported that no stem cells were isolated from cord blood samples which preparation time exceeded 15 hours. In our, so far unpublished, results of analysis of cord blood collected from deliveries by cesarean section, the fall of telomerase expression in MSC occurs 12 hours after collection. Concurrence of those two observations seems to confirm that impairment of stem cells ability to express telomerase leads to their apoptosis and subsequent decrease in their number. Taking that into consideration there are reasons to believe that preparation process of cord blood collected during physiological labour should finish before the fall of expression of telomerase revealed in our study, namely before 6 hours from collection. Longer time leads to decrease of MSC count and impairment of stem cells "quality".

\section{References}

[1] Lee MK, Hande MP, Sabapathy K. Ectopic mTERT expression in mouse embryonic stem cells does not affect differentiation but confers resistance to differentiation- and stressinduced p53-dependent apoptosis. J Cell Sci. 2005;118(Pt 4):819-29.

[2] Armstrong L, Saretzki G, Peters H et al. Overexpression of telomerase confers growth advantage, stress resistance, and enhanced differentiation of ESCs toward the hematopoietic lineage. Stem Cells. 2005;23(4):516-29.

[3] Murasawa S, Llevadot J, Silver M, Isner JM, Losordo DW, Asahara T. Constitutive human telomerase reverse transcriptase expression enhances regenerative properties of endothelial progenitor cells. Circulation. 2002;106(9):1133-9.

[4] Huang XQ, Wang J, Liu JP et al. hTERT extends proliferative lifespan and prevents oxidative stress-induced apoptosis in human lens epithelial cells. Invest Ophthalmol Vis Sci. 2005;46(7):2503-13.

[5] Kang HJ, Choi YS, Hong SB et al. Ectopic expression of the catalytic subunit of telomerase protects against brain injury resulting from ischemia and NMDA-induced neurotoxicity. $J$ Neurosci. 2004;24(6):1280-7.

[6] Luiten RM, Pene J, Yssel H, Spits H. Ectopic hTERT expression extends the life span of human $\mathrm{CD} 4+$ helper and regulatory T-cell clones and confers resistance to oxidative stressinduced apoptosis. Blood. 2003;101(11):4512-9.

[7] Schoppmann SF, Soleiman A, Kalt R et al. Telomeraseimmortalized lymphatic and blood vessel endothelial cells are 
functionally stable and retain their lineage specificity. Microcirculation. 2004;11(3):261-9.

[8] Condon J, Yin S, Mayhew B et al. Telomerase immortalization of human myometrial cells. Biol Reprod. 2002;67(2):506-14.

[9] Huang XQ, Wang J, Liu JP et al. hTERT extends proliferative lifespan and prevents oxidative stress-induced apoptosis in human lens epithelial cells. Invest Ophthalmol Vis Sci. 2005;46(7):2503-13.

[10] Colitz CM, Whittington A, Carter R, Warren J. The effects of oxidative stress on telomerase activity and other stress-related proteins in lens epithelial cells. Exp Eye Res. 2004;78(2):235-42.

[11] Nishi H, Nakada T, Kyo S, Inoue M, Shay JW, Isaka K. Hypoxia-inducible factor 1 mediates upregulation of telomerase (hTERT). Mol Cell Biol. 2004;24(13):6076-83.

[12] Seimiya H, Tanji M, Oh-hara T, Tomida A, Naasani I, Tsuruo T. Hypoxia up-regulates telomerase activity via mitogen-activated protein kinase signaling in human solid tumor cells. Biochem Biophys Res Commun. 1999;260(2):365-70.

[13] Minamino T, Mitsialis SA, Kourembanas S. Hypoxia extends the life span of vascular smooth muscle cells through telomerase activation. Mol Cell Biol. 2001;21(10):3336-42.

[14] Milosevic J, Schwarz SC, Krohn K, Poppe M, Storch A, Schwarz J. Low atmospheric oxygen avoids maturation, senescence and cell death of murine mesencephalic neural precursors. J Neurochem. 2005;92(4):718-29.

[15] Mears K, McAuliffe F, Grimes H, Morrison JJ. Fetal cortisol in relation to labour, intrapartum events and mode of delivery. J Obstet Gynaecol. 2004;24(2):129-32.

[16] Vogl SE, Worda C, Egarter C et al. Mode of delivery is associated with maternal and fetal endocrine stress response. BJOG. 2006;113(4):441-5.

[17] Miller NM, Fisk NM, Modi N, Glover V. Stress responses at birth: determinants of cord arterial cortisol and links with cortisol response in infancy. BJOG. 2005;112(7):921-6.

[18] Malamitsi-Puchner A, Protonotariou E, Boutsikou T, Makrakis E, Sarandakou A, Creatsas G. The influence of the mode of delivery on circulating cytokine concentrations in the perinatal period. Early Hum Dev. 2005;81(4):387-92.

[19] Ferber A, Minior VK, Bornstein E, Divon MY. Fetal "nonreassuring status" is associated with elevation of nucleated red blood cell counts and interleukin-6. Am J Obstet Gynecol. 2005;192(5):1427-9.

[20] Marchini G, Hagenas L, Kocoska-Maras L, Berggren V, Hansson LO. Insulin-like growth factor binding protein-1 and interleukin- 6 are markers of fetal stress during parturition at term gestation. J Pediatr Endocrinol Metab. 2005;18(8):77783.

[21] Ma Y, Zou P. Zhonghua Nei Ke Za Zhi. The expression of human telomerase reverse transcriptase gene in cord blood hematopoietic stem cells and its significance. 2001;40(10):657-9

[22] Akiyama M, Hideshima T, Hayashi T et al. Cytokines modulate telomerase activity in a human multiple myeloma cell line. Cancer Res. 2002;62(13):3876-82.

[23] Yamagiwa Y, Meng F, Patel T. Interleukin-6 decreases senescence and increases telomerase activity in malignant human cholangiocytes. Life Sci. 2006;78(21):2494-502. Epub 2005 Dec 5.

[24] Chaves-Dias C, Hundley TR, Gilfillan AM et al. Induction of telomerase activity during development of human mast cells from peripheral blood CD34+ cells: comparisons with tumor mast-cell lines. J Immunol. 2001;166(11):6647-56.

[25] Encabo A, Mateu E, Carbonell-Uberos F, Minana MD. IL-6 precludes the differentiation induced by IL-3 on expansion of CD34+ cells from cord blood. Haematologica. 2003;88(4):388-95.

[26] Engelhardt M, Kumar R, Albanell J, Pettengell R, Han W, Moore MA. Telomerase regulation, cell cycle, and telomere stability in primitive hematopoietic cells. Blood. 1997;90(1):182-93.

[27] Nakagawa R, Watanabe T, Kawano Y et al. Chugoku-Shikoku Cord Blood Bank. Analysis of maternal and neonatal factors that influence the nucleated and CD34+ cell yield for cord blood banking. Transfusion. 2004;44(2):262-7.

[28] Bieback K, Kern S, Kluter H, Eichler H. Critical parameters for the isolation of mesenchymal stem cells from umbilical cord blood. Stem Cells. 2004;22(4):625-34.

Submitted: 24 February, 2009 Accepted after reviews: 3 May, 2009 